\title{
ANALISA FAKTOR-FAKTOR PENENTU BUDGETARY SLACK PADA LEMBAGA SWADAYA MASYARAKAT (STUDI EMPIRIS DENGAN MENGGUNAKAN STRUCTURALEQUATION MODELING)
}

\author{
Maria Eurelia Wayan ${ }^{1}$ \\ ${ }^{\prime}$ Tenaga Pengajar Universitas Indonesia
}

\begin{abstract}
Abstrak - Penelitian ini bertujuan untuk mengkaji faktor-faktor penentu budgetary slack pada Lembaga Swadaya Masyarakat. Pengujian dilakukan dengan menggunakan metode Structural Equation Modeling (SEM). Penelitian ini menemukan bukti bahwa faktor budgetary participation, tuntutan akuntabilitas, asimetri informasi, dan perilaku individu LSM mempengaruhi budgetary slack. Ditemukan pula adanya korelasi antara budgetary participation, tuntutan akuntabilitas, asimetri informasi dan perilaku individu LSM. Penelitian ini menggunakan metode survei dengan 210 responden dari unit analisa individual yaitu direktur dan manajer LSM.
\end{abstract}

Kata Kunci: Akuntabilitas, Asimetri Informasi, Budget, Perilaku.

This study aims to examine the determinants of budgetary slack on NGOs. Tests performed by using Structural Equation Modeling (SEM). This study found evidence that factors budgetary participation, accountability demands, information asymmetry, and the behavior of individual NGOs affect budgetary slack. Also found a correlation between budgetary participation, accountability demands, information asymmetry and the behavior of individual NGOs. This study uses a survey with 210 respondents of the unit of analysis is the individual directors and managers of NGOs.

Keywords: Accountability, Information Asymmetry, Budget, Behavior.

\section{PENDAHULUAN}

\section{Latar Belakang}

Salah satu fungsi yang dimiliki oleh Lembaga Swadaya Masyarakat (LSM) adalah peran dalam pemberdayaan masyarakat untuk mengangkat komunitas marginal dari segala permasalahannya. Di negara berkembang, pemerintah yang selayaknya memperhatikan harkat hidup masyarakat seringkah tidak menjalankan tugas itu sebagaimana mestinya. Pemerintah, dalam menjalankan tugasnya mengayomi masyarakat, membutuhkan pelaku bisnis untuk ikut mengangkat harkat martabat mereka dengan menyediakan lapangan pekerjaan dan memberikan penghargaan kepada masyarakat untuk hidup yang layak. Pada kenyataannya pemerintah lebih memihak pada kepentingan pelaku bisnis daripada masyarakat dan bekerja sama dengan pelaku bisnis untuk kepentingan pribadi. Pengawasan pemerintah yang seharusnya dilakukan terhadap pelaku bisnis tidak terjadi. Pemerintah menjadi kurang transparan dalam mengimplementasikan kebijakankebijakannya. Hal ini mengakibatkan pengawasan masyarakat terhadap kinerja pemerintah menjadi lemah.

Menurut Masyarakat Transparansi Indonesia (MTI, 2005), gerakan antikorupsi 
yang dipelopori oleh LSM ternyata belum dapat berbuat banyak meski sejumlah kasus berhasil didorong hingga ke pengadilan. LSM memiliki tanggung jawab sosial untuk memberikan contoh yang baik dalam hal transparansi yang diartikan sebagai suatu sistem yang terpercaya (credible) dan dapat dipertanggungjawabkan \{accountable). Kehadiran LSM merupakan suatu mitra bagi para pelaku bisnis, politisi, dan pemerintah dalam penerapan kebijakannya agar dapat pula menjalankan prinsip yang sama seperti yang dijalankan oleh LSM.

Menurut data Lembaga Penelitian, Pendidikan dan Penelitian Ekonomi dan Sosial (LP3ES, website LP3ES mengenai direktori piecebuilding Indonesia pada tanggal 18 April 2007) saat ini terdapat lebih dari 50.000 LSM diseluruh penjuru dunia dan 746 LSM di Indonesia. Oleh karenanya, para pelaku bisnis, politisi, dan pemerintah perlu menyadari akan tindakan atau kebijakan yang mereka lakukan karena LSM sebagai mitra akan mengikuti perkembangan kemitraan yang selama ini telah berjalan. Demi kepentingan masyarakat umum, LSM meminta para pelaku bisnis, politisi, dan pemerintah untuk lebih terbuka dan transparan akan segala tindakan dan kebijakan yang mereka ambil.

Dalam menjalankan peran tersebut LSM memperoleh bantuan dana dari berbagai pihak (penyandang/pemberi dana) sesuai dengan usulan anggaran (selanjutnya akan disebut budget) yang diajukan. LSM dituntut untuk memberikan laporan yang accountable atas dana yang dikelolanya tersebut, dimana laporan harus sesuai dengan budget yang telah disepakati bersama, dan tidak menyimpang dari aturan pemerintah lokal. Di Indonesia laporan keuangan yang harus dibuat tersebut diatur dalam Pernyataan Standar Akuntansi Keuangan (PSAK) Nomor 45 (IAI, 2004) mengenai pelaporan keuangan untuk organisasi nirlaba. PSAK No.45 membahas khusus mengenai laporan keuangan organisasi nirlaba, antara lain laporan posisi keuangan, laporan aktivitas, laporan arus kas, dan tanggal efektif berlakunya PSAK ini.

Menjamurnya LSM di Indonesia, khususnya pasca bencana tsunami pada 26 Desember 2004, gempa di Yogyakarta dan lumpur panas Sidoarjo setahun yang lalu, banjir dan bencana lainnya akibat pemanasan global, dalam kenyataannya nampak belum cukup diikuti dengan pola laporan yang accountable sesuai yang diharapkan oleh berbagai pihak yang berkepentingan, khususnya pihak pemberi dana. Hal tersebut kemungkinan diakibatkan karena LSM yang muncul umumnya bukanlah organisasi berbasis keanggotaan, tidak berasal dari institusi pemerintah atau memiliki kemandirian dalam hal keuangan (Fowler, 2000a, dalam Kilby, 2004). LSM dijalankan oleh sejumlah staf atau sejumlah kecil anggota yang memiliki kecenderungan untuk melihat peran penting LSM dalam masyarakat dan berupaya mempromosikan ide atau nilai dalam pengentasan masyarakat yang terpinggirkari, sehingga mengabaikan pencapaian target budget dan pembuatan laporan keuangan yang baik (Salamon et al, 2000) sesuai dengan budget. Implikasinya adalah LSM tersebut kemudian menemui kesulitan dalam memperoleh dana lebih lanjut atau akhirnya memperoleh dana tersebut setelah melalui 
proses diskusi yang menghabiskan waktu dan tenaga seputar budget (Mango, 2006).

Kasus LSM yang mendapat hambatan atau penolakan dari pihak pemberi dana adalah hal yang umum terjadi. Kasus berikut ini merupakan salah satu contoh dimana sebuah LSM telah mendapat signal, dari pihak pemberi dana, akan segera menerima dana untuk segera memulai program kerjanya namun akhirnya batal memperoleh dana ${ }^{1}$. Berdasarkan hasil berbagai pertemuan dengan pihak pemberi dana, LSM tersebut memperbaiki proposal program dan budget beserta kelengkapannya seperti standard operation procedure keuangan, deskripsi kerja, sistem pemantauan dan evaluasi program. Pihak pemberi dana memberi persetujuan atas revisi proposal yang sudah lengkap dan memorandum of understanding (MOU) siap ditandatangani setelah kerja keras selama lebih kurang tujuh bulan. Menjelang penandatanganan $\mathrm{MOU}$, timbul masalah terkait dengan budget sehingga LSM tersebut dianggap tidak konsisten dengan proposal yang telah disepakati. Ketidakkonsistenan itu menimbulkan keraguan di pihak pemberi dana akan kemampuan LSM mencapai target budget dan melaporkan hasil sesuai dengan budget. Kemitraan kerja yang hendak dibangun dibatalkan atau dengan kata lain proyek batal memperoleh dana senilai lebih dari satu milyar rupiah.

Jadi tampak bahwa budget memegang peranan penting dalam upaya LSM untuk mengangkat permasalahan yg dimiliki oleh masyarakat luas. Budget menjadi tolak ukur akan akuntabilitas dan kinerja LSM. Oleh karena itu penyusunan budget merupakan suatu hal yang sangat penting bagi LSM demi kelangsungan hidup organisasi tersebut. Akuntabilitas dapat mempengaruhi kerja LSM dalam menjalankan perannya sebagai lembaga yang berupaya memberdayakan masyarakat umum semaksimal mungkin. LSM terikat kontrak dengan pihak pemberi dana, sehingga mereka akan berupaya untuk mencapai standar akuntabilitas yang diminta oleh pihak pemberi dana \{upward accountability: Kilby ,2004). Implikasinya, tidak jarang terjadi LSM tidak menjalankan peranan mereka sebagai lembaga yang berperan memberdayakan masyarakat, dimana mereka memiliki tanggung jawab yang sama kepada masyarakat yang diberdayakannya dalam hal akuntabilitas \{downward accountability: Kilby, 2004). Dilema ini harus disikapi LSM, apalagi tidak terdapat ketentuan khusus, dari segi hukum atau peraturan pemerintah maupun pihak pemberi dana, yang mengharuskan LSM untuk pula akuntabel kepada masyarakat yang diberdayakannya.

Budget dibuat berdasarkan keputusan dan partisipasi yang kolektif (Titi dan Singh, 1995). Dengan adanya budgetary participation (partisipasi penganggaran) diharapkan budget yang dibuat dapat disesuaikan dengan kebutuhan dari masing-masing divisi dalam suatu proyek. Berdasarkan masukan dari masing-masing divisi tersebut, diharapkan semua informasi yang didapatkan, tidak mengakibatkan informasi yang asimetri. Dengan demikian proses penyusunan budget 
melibatkan masukan dari bawahan untuk memperoleh informasi yang sejelas-jelasnya dan dipengaruhi oleh perilaku individu dalam organisasi berkaitan dengan misi organisasi dalam peningkatan harkat masyarakat yang diperjuangkan. Perilaku individu dalam penelitian ini dikaitkan dengan motivasi, budaya, dan komitmen individu yang memiliki kemungkinan berbeda dengan organisasi.

Dalam prakteknya, tidak seluruh individu dalam organisasi yang ikut berpartisipasi dalam penyusunan budget \{budgetary panicipation) memberikan semua informasi yang ada (asimetri informasi) sehingga menimbulkan budgetary slack. Slack umumnya terjadi adalah dengan meninggikan biaya sehingga misi yang dijalankan tidak terhenti di tengah jalan, namun mudah dalam membuat laporan yang accountable sesuai dengan anggaran. Dengan demikian slack yang ada digunakan untuk tujuan tertentu atau disimpan untuk dapat dipergunakan di kemudian hari pada saat kekurangan dana atau terdapat keperluan dana mendesak (Cyert dan March, 1963 dalam Merchant 1985).

Penelitian yang dilakukan oleh Schiff dan Lewin (1970) dan Leibenstein (1979) membuktikan pula bahwa slack biasa terjadi di banyak organisasi. Besarannya sekitar 20 $25 \%$ dari beban operasi divisi yang dianggarkan (Schiff dan Lewin, 1968 dalam Merchant, 1985) atau $30-40 \%$ dari beban aktual (Leibenstein, 1979 dalam Merchant, 1985). Hasil penelitian Onsi (1973) menunjukkan bahwa 80\% manajer, dari lima perusahaan, yang menjadi responden menyatakan mereka membutuhkan slack. Slack ini dipengaruhi oleh faktor behavioural seperti mengapa dan bagaimana slack diciptakan dan bagaimana tanggapan top management akan hal ini (Onsi, 1973). Perilaku manajer yang berupaya menciptakan slack berkaitan dengan kepentingan manajer sebagai individu yang rasional (Lowe dan Shaw, 1968 dalam Merchant, 1985). Onsi (1973) berhasil mengembangkan kuesioner berkaitan dengan perilaku manajemen terkait dengan budgets, budget pressure, dan budgetary slack.

Dalam kasus LSM, pihak pemberi dana akan secara ketat memonitor kinerja LSM berdasarkan budget. Pihak pemberi dana umumnya telah memiliki standar budget baik untuk direct cost maupun indirect cost yang dapat diterima oleh pemberi dana tersebut (Mango, 2006). Dengan demikian jika terjadi slack maka umumnya berada dalam koridor standar budget menurut pihak pemberi dana. Implikasinya LSM akan mengajukan budget sedemikian rupa guna memudahkan dalam membuat laporan yang memuaskan pihak pemberi dana, sehingga bersedia memberikan dana kembali bagi proyek selanjutnya.

Penelitian terdahulu yang berkaitan dengan budgetary slack sudah banyak dilakukan dengan hasil yang berbeda-beda. Slack dipengaruhi oleh asimetri informasi (antara lain Fitri 2004; Dunk, 1993; Young, 1985), budgetary emphasis (Dunk, 1993; Merchant, 1985; Onsi, 1973), budgetary participation (antara lain Fitri, 2004; Dunk, 1993; Merchant, 1985), dan ketidakpastian lingkungan (antara lain Kren dan Liao, 1988; Govindarajan, 1986; Cyert dan March, 1963). 
Selain itu banyak potensial antecedents dari slack untuk diuji seperti budaya organisasi, motivasi, dan komitmen organisasi (Dunk dan Nouri, 1998) dan penggunaan broad scope managerial accounting system (MAS) yang diyakini dapat meningkatkan kinerja (Linn et al, 2001).

Penelitian mengenai tuntutan akuntabilitas LSM juga sudah banyak dilakukan (antara lain Kilby, 2004; Antonioni, 1994). Survei terhadap akuntabilitas LSM pun pernah dilakukan oleh Keystone (2006). Namun penelitian berkaitan dengan tuntutan akuntabilitas LSM dan slack khususnya masih jarang ditemui. Oleh karena itu penelitian ini berupaya untuk meneliti kaitan antara budgetary participation, asimetri informasi, tuntutan akan akuntabilitas, serta perilaku individu dalam organisasi terhadap budgetary slack dengan metode penelitian survei pada LSM.

\section{Pertanyaan Penelitian}

LSM sebagai lembaga yang berperan mengawasi segala tindakan para pelaku bisnis, politisi ataupun pemerintah demi kepentingan masyarakat umum tidak selamanya berlaku lebih baik dari yang mereka awasi. Masyarakat umum sering berpendapat bahwa LSM dalam menjalankan misinya, bebas dari campur tangan pemberi dana atau kepentingan dari luar yang memiliki kekuasan yang lebih besar.

Berkaitan dengan peran yang dijalankannya, LSM mendapatkan pula pendanaan dari pihak pemerintah, politisi atau organisasi bisnis (baik lokal maupun asing) yang diawasinya. Keringanan dalam hal pajak dan memperoleh berbagai kemudahan dalam berhubungan dengan pihak media atau pemerintah pun menjadi perlakuan istimewa bagi LSM. Dalam prakteknya dikhawatirkan LSM akan kehilangan obyektilrtasnya. Oleh karena itu, LSM diharapkan dapat memberikan contoh yang baik dalam hal akuntabilitas dan transparansi sebelum melakukan koreksi atau tuntutan terhadap pihak lain untuk melakukan hal yang sama.

Berdasarkan pemikiran di atas dan pengawasan dari pihak pemberi dana akan kinerja LSM berdasarkan budget, maka peneliti berusaha untuk melakukan penelitian apakah LSM di Indonesia sudah melakukan kewajibannya dalam melaporkan kegiatan dan keuangannya kepada pihak pemberi dana dan masyarakat umum secara transparan. Penelitian ini akan menggunakan data primer berkaitan dengan budget dan akuntabilitas LSM di Indonesia, khususnya di Jawa dan Sumatra yang sepanjang tahun 2000-an berturut-turut mengalami bencana, untuk menjawab pertanyaan-pertanyaan sebagai berikut:

1. Bagaimana pengaruh budgetary participation terhadap budgetary slack?

2. Bagaimana pengaruh asimetri informasi terhadap budgetary slack?

3. Bagaimana pengaruh tuntutan akuntabilitas terhadap budgetary slack?

4. Bagaimana pengaruh perilaku individu LSM terhadap budgetary slack?

5. Bagaimana hubungan antara budgetary participation dengan asimetri informasi, tuntutan akuntabilitas, dan perilaku 
individu LSM?

\section{Tujuan Penelitian}

Penelitian berkaitan dengan budgetary slack dikaitkan dengan budgetary participation, asimetri informasi, dan perilaku sudah cukup banyak dilakukan. Demikan pula halnya dengan penelitian mengenai akuntabilitas dan transparansi. Namun penelitian mengenai budgetary slack dan tuntutan akuntabilitas dikaitkan dengan LSM masih kurang banyak dijumpai. Banyak hal yang perlu diperhatikan dan disempurnakan baik oleh LSM itu sendiri maupun pihak pemberi dana berkaitan dengan akuntabilitas. Oleh karenanya tujuan peneliti dalam memilih issue ini :

1. Menguji dan menganalisa pengaruh budgetary participation, asimetri informasi, tuntutan akuntabilitas, dan perilaku individu LSM terhadap budgetary slack.

2. Menguji dan menganalisa hubungan antara budgetary participation, asimetri informasi, tuntutan akuntabilitas, dan perilaku individu LSM.

3. Secara khusus, penelitian ini bertujuan untuk memberikan pemahaman yang lebih baik mengenai pentingnya akuntabilitas yang dilakukan oleh LSM, pengaruhnya terhadap budgetary slack, dan manfaatnya bagi banyak pihak khususnya LSM itu sendiri dalam meningkatkan kinerjanya, pihak pemberi dana, serta masyarakat umum yang akan diberdayakan.

\section{Metode Penelitian}

Berdasarkan pertanyaan dan tujuan, maka peneliti mengembangkan hipotesa mengenai hubungan antara budgetary participation, asimetri informasi, tuntutan akuntabilitas, serta perilaku individu dalam organisasi dengan budgetary slack, yang dapat digunakan sebagai evaluasi atas kinerja LSM. Dalam penelitian tersebut akan diuji mengenai pengaruh budgetary participation, asimetri informasi, tuntutan akuntabilitas, dan potensial antecedents yaitu perilaku individu dalam organisasi, terhadap budgetary slack. Pengujian pula dilakukan untuk melihat hubungan antara keempat variabel yang mempengaruhi budgetary slack. Uji hipotesa dilakukan dengan teknik model persamaan struktural \{Structural Equation Modeling, SEM) dengan menggunakan data primer yang dikumpulkan dari para direktur dan manajer dari beberapa LSM di Indonesia khususnya Jawa dan Sumatra.

\section{ANALISIS DAN PEMBAHASAN}

Berdasarkan statistik deskriptif pada bab III yang menunjukkan data-data yang tidak terdistribusi secara normal, maka pada waktu pengolahan data dengan SEM dilakukan normalisasi data lebih dahulu. Hal ini harus dilakukan karena merupakan persyaratan dalam penggunaan SEM (Wijanto, 2006).

\section{a. Analisa Validitas Model Pengukuran}

Hasil pengolahan data penelitian dengan program LISREL 8.72 full version menghasilkan gambar hubungan model struktural yang disajikan pada gambar 4.1. (gambar 4.1. merupakan hasil output LISREL dengan parameter hasil estimasi 
Standardized Solution. Pola hubungan beserta data statistik yang menyertai kesesuaian model tidak diperoleh dalam satu kali proses namun dilakukan berulang kali sambil mengoreksi beberapa variabel teramati, yang memiliki loading factor kurang dari 0,50 tidak dapat dipergunakan (Igbaria et als 1997 dan Hair et al, 1995 dalam Wijanto, 2006), untuk mencapai hasil yang optimal (gambar 4.2.). Proses ${ }^{\wedge}$ me-luning terhadap program SIMPLIS dari gambar 4.1. hingga menghasilkan gambar 4.2. dapat dilihat pada Lampiran 2.

Pada gambar 4.1. menunjukkan validitas dari tiap variabel teramati untuk setiap konstruk. Terlihat bahwa nilai loading factor dari variabel ukur (teramati) yang membentuk konstruk budgetary participation bernilai cukup besar yaitu berkisar dari -0.06 (paling kecil untuk Q10) hingga 0.81 (paling besar untuk Q8). Ada satu variabel teramati yang mempunyai nilai loading factor negatif terhadap konstruk. Jadi untuk konstruk budgetary participation terdapat 4 variabel teramati yang sangat signifikan yaitu Q8, Q9, Q11, dan Q12.

Seluruh variabel teramati atau pertanyaan yang membentuk konstruk asimetri informasi memiliki nilai loading factor lebih dari 0,50. Nilai loading factor terkecil dari konstruk asimetri informasi yaitu 0.56 (untuk Q21) dan nilai tertinggi yaitu 0.83 (untuk Q1 8). Jadi untuk konstruk asimetri informasi ini seluruh pertanyaan (6 variabel teramati) sangat signifikan yaitu Q16 hingga Q12.

Untuk konstruk tuntutan akan akuntabilitas, variabel ukur (teramati) yang membentuk konstruk memiliki nilai loading factor yang relatif kecil yaitu berkisar antara 0.28 (nilai terkecil untuk Q28) hingga 0.87 (nilai terbesar untuk Q25). Namun tidak terdapat variabel teramati yang mempunyai nilai loading factor negatif terhadap konstruk. Konstruk ini diukur dengan delapan variabel teramati dan dari ke-8 variabel teramati tersebut hanya empat variabel teramati yang sangat signifikan yaitu Q22, Q24, Q25 hingga Q26.

Nilai loading factor untuk variabel ukur (teramati) yang membentuk konstruk perilaku individu LSM bernilai relatif besar yaitu berkisar antara 0.33 (nilai paling kecil pada Q32) hingga 0.85 (nilai paling.besar pada Q31). Seluruh variabel teramati memiliki nilai loading factor positif terhadap konstruk. Variabel teramati yang sangat signifikan hanya tiga yaitu Q30, Q31, dan Q33, dari lima variabel teramati.

Seluruh variabel teramati atau pertanyaan yang membentuk konstruk budgetary slack memiliki nilai loading factor yang relatif kecil. Nilai loading factor yang sangat signifikan di atas 0,50 hanya terlihat pada dua variabel teramati yaitu Q38 dan Q39. Sisanya (tujuh variabel teramati) memiliki nilai loading factor di bawah 0,50 dengan nilai terkecil dari konstruk ini yaitu 0.12 (untuk Q37)dan nilai tertinggi yaitu 0.78 (untuk Q39). Total variabel teramati berjumlah 36, namun yang memiliki nilai loading factor yang sangat signifikan setelah melalui proses fine-tuning terhadap program SIMPLIS adalah 19 variabel teramati. Hal ini menandakan bahwa data sampel cukup baik. 
Total 19 variabel teramati tersebut dapat dilihat pada gambar 4.1.di bawah ini.

\section{b. Analisa Pengujian Keseluruhan Model}

Pengujian kesesuaian keseluruhan model ini dapat dilihat pada tabel 4.1. Pengujian ini berdasarkan daftar ukuran goodness of 'fit yang dikompilasi dari Hair et al (1995), Chin dan Todd (1985), Doll, Xia, dan Torkzadeh (1994), Joreskog dan Sorbom (1993) dan Byrne (1998) dalam Wijanto (2006.)

Tabel 4.1.

Goodness of Fit Keseluruhan Model

\begin{tabular}{|c|c|c|c|}
\hline Ukuran Goodness of Fit & $\begin{array}{c}\text { Target-Tingkat } \\
\text { Kesesuaian }\end{array}$ & Hasil Estimasi & $\begin{array}{r}\text { Tingkat } \\
\text { Kesesuaian }\end{array}$ \\
\hline Chi-Square P & $\begin{array}{l}\text { Nilai yang kecil } p> \\
0.05\end{array}$ & $\begin{array}{l}335.37 \mathrm{p}= \\
0.0\end{array}$ & Kurang baik \\
\hline NCP Interval & $\begin{array}{l}\text { Nilai yang kecil Interval } \\
\text { yang sempit }\end{array}$ & $\begin{array}{l}166.53119 .66- \\
221.15\end{array}$ & Kurang Baik \\
\hline RMSEA p (close fit) & $\begin{array}{l}\text { RMSEA < } 0.08 \mathrm{p}> \\
0.05,\end{array}$ & $\begin{array}{l}0.075 \\
0.00028\end{array}$ & $\begin{array}{l}\text { Baik Not } \\
\text { Fit }\end{array}$ \\
\hline ECVI & $\begin{array}{l}\text { Nilai yang kecil dan dekat } \\
\text { dengan ECVI saturated }\end{array}$ & $\begin{array}{l}\mathrm{M}=1.94 \mathrm{~S} \\
=1.82 \\
1=14.73\end{array}$ & \begin{tabular}{|l|} 
Baik \\
Good fit
\end{tabular} \\
\hline$\overline{A I C}$ & $\begin{array}{l}\text { Nilai yang kecil dan dekat } \\
\text { dengan AIC saturated }\end{array}$ & $\begin{array}{l}\mathrm{M}=404.53 \mathrm{~S}= \\
380.00 \mathrm{I}= \\
3079.29\end{array}$ & \begin{tabular}{|l} 
Baik \\
Good fit
\end{tabular} \\
\hline CAIC & $\begin{array}{l}\text { Nilai yang kecil dan dekat } \\
\text { dengan CAIC saturated }\end{array}$ & $\begin{array}{l}\mathrm{M}=613.20 \mathrm{~S}= \\
1205.951= \\
3161.88\end{array}$ & $\begin{array}{l}\text { Baik Good } \\
\text { fit }\end{array}$ \\
\hline NFI & $\mathrm{NFI}>0.90^{\bullet}$ & 0.89 & Cukup Baik \\
\hline NNFI & NNFI $>0.90$ & 0.92 & Baik (good fit) \\
\hline CFI & CFI $>0.90$ & 0.93 & Baik (good fit) \\
\hline IFI & IFI $>0.90$ & 0.93 & Baik (good fit) \\
\hline RFI & RFI $>0.90$ & 0.87 & Cukup Baik \\
\hline$\overline{\mathrm{PNFI}}$ & PNFI $>0.90$ & 0.74 & Kurang Baik \\
\hline $\mathrm{CN}$ & $\mathrm{CN}>200$ & 115.74 & $\begin{array}{l}\text { Kurang Baik } \\
\text { (not fit) }\end{array}$ \\
\hline$\overline{\mathrm{RMR}}$ & Standardized RMR $<0.05$ & 0.12 & Kurang Baik \\
\hline $\bar{C}$ 'iFI & GFI > 0.90 & 0.87 & Cukup Baik \\
\hline AGFI & AGFI $>0.90$ & 0.82 & Cukup Baik \\
\hline PGFI & PGFI $>0.90$ & 0.65 & Kurang Baik \\
\hline
\end{tabular}

M = Model; S = Saturated; I = Independence

Berdasarkan tabel 4.1, maka dapat disimpulkan bahwa keseluruhan model cukup baik. Hasil tersebut disimpulkan berdasarkan kombinasi antara baik (tujuh parameter), cukup baik (empat parameter), dan kurang baik (enam parameter). Chi Square sebesar 335,37 ( $=0,00)$ menunjukkan bahwa kesesuaian kurang baik karena Chi Square besar dan nilai p nol. Persyaratan signifikansi yang baik mengikuti statistik adalah jika Chi Square kecil, dimana 
semakin kecil maka signifikansinya semakin baik. Nilai NCP sebesar 166,53 yang besar dengan Confidence interval NCP sebesar 119,66 - 221,15 menunjukkan interval yang lebar berarti tingkat kesesuaian kurang baik. Persyaratan model yang baik sama halnya dengan Chi Square, dimana semakin kecil NCP maka semakin baik model karena semakin kecil perbedaan pada setiap observasi. Namun nilai RMSEA sebesar 0,075 menunjukkan model baik. RMSEA menunjukkan rata-rata perbedaan per degree of freedom yang diharapkan terjadi dalam populasi dan bukan hanya dalam sampel. Tingkat kesesuaian baik karena kurang dari 0,08 namun tidak close fit, p yang kecil yaitu 0,00028, dengan confidence interval 90\% (penilaian terhadap presisi dari estimasi RMSEA yaitu 0,063 - 0,086).

ECVI model (1,94) jika dibandingkan dengan ECVI saturated model $(1,82)$ dan ECVI independence model $(14,73)$ maka ECVI model mendekati saturated model. Terlihat ECVI model sedikit lebih kecil jika dibandingkan dengan ECVI saturated model dan jauh lebih kecil dari ECVI independence model dengan confidence internal 90\% adalah 1,71 sampai 2,20. Nilai kesesuaian ini makin baik jika nilainya semakin kecil. Dengan demikian kesesuaian yang diperoleh adalah baik.

AIC model $(404,53)$ jika dibandingkan dengan AIC saturated model (380,00) dan AIC independence model $(3079,29)$ maka AIC model mendekati saturated model. Terlihat AIC model sedikit lebih kecil jika dibandingkan dengan AIC saturated model dan jauh lebih kecil dari AIC independence model. Jadi dapat disimpulkan model baik. Begitu pula menurut CAIC. CAIC model (613,20) jika dibandingkan dengan C AIC saturated model $(1205,95)$ dan CAIC independence model $(3161,88)$ maka C AIC model mendekati saturated model. Terlihat CAIC model lebih kecil jika dibandingkan dengan CAIC saturated model dan jauh lebih kecil dari CAIC independence model. Semakin kecil nilai AIC dan CAIC semakin baik.

NFI memiliki nilai 0,89 (mendekati 0,90) dan CFI memiliki nilai 0,93 (lebih besar dari 0,90). Kedua nilai ini dapat dikatakan menunjukkan good fit (model yang baik). Begitu pula halnya dengan NNFI sebesar 0,92 dan IFI bernilai 0,93 (keduanya bernilai lebih besar dari 0,90) menunjukkan model baik. Nilai RFI yaitu 0,87 yang mendekati 0,90 dapat dikatakan konsisten terhadap CFI (Nilai RFI menunjukkan marginal fit). Hal ini juga menunjukkan model baik (good fit) kecuali PNFI yang nilainya 0,74 berada di bawah marginal fit.

Namun Critical N (CN) sebesar 115,74 (lebih kecil dari 200) menunjukkan bahwa model ternyata kurang mewakili sampel data dengan RMR yang merupakan nilai rata-rata residual hasil dari fitting antara variancecovariance matrix dari model dengan variancecovariance matrix dari sampel data menunjukkan kesesuaian kurang baik (0,12 > 0,05). Yang baik (good fit) jika model memiliki RMR kurang dari 0,05. CiFI sebesar 0,87 mendekati 0,90 menunjukkan model baik (marginal fit) begitu pula dengan AGFI (0.82). Namun PGFI 0,65 menunjukkan model 
kurang

baik

karena

semakin tinggi nilai GFI maka semakin baik.

Rasio antara Chi Square dibagi dengan degree of freedom memiliki nilai 2,36. Rasio ini menunjukkan model baik pada batas atas yaitu antara $2,0-3,0$.

\section{c. Analisa Kesesuaian Reliabilitas Model Pengukuran}

Berdasarkan prosedur SEM yang harus dijalankan yang telah dipaparkan pada bab III perlu dilakukan pengujian kesesuaian atas model pengukuran. Analisa dilakukan terhadap evaluasi setiap konstruk secara terpisah untuk menguji reabilitas dari suatu konstruk. Hasil pengujian dapat dilihat pada tabel 4.2. Teknik pengujian reliabilitas dengan Cronbach 's alpha telah disajikan pada bab sebelumnya (bab 3) dan menunjukkan bahwa 210 data survei yang diperoleh menunjukkan reliabilitas yang baik dengan nilai Cronbach 's alpha 0,888 yang berarti mendekati 1. Hal ini sejalan dengan pernyataan Sekaran (2003). Pengukuran reliabilitas untuk SEM dilakukan dengan menggunakan construct reliability dan variance extracted yang dapat dilihat pada tabel 4.2. di atas. Nilai reliabilitas yang baik adalah jika nilai construct reliability lebih besar atau sama dengan 0,70 dan variance extracted memiliki nilai lebih besar atau sama dengan 0,50 (Hairef a/, 1995 dalam Wijanto, 2006). Berdasarkan tabel tersebut tampak bahwa reliabilitas untuk konstruk budgetary participation adalah baik $(0,79)$. Demikian pula halnya dengan keempat konstruk lainnya yaitu asimetri informasi (0,83), tuntutan akan akuntabilitas (0,73), perilaku individu LSM (0,78), dan budgetary slack (0,70). Reliabilitas seluruh konstruk lebih besar atau sama dengan 0,70 berarti keseluruhan konstruk memiliki reliabilitas yang baik. Sementara nilai variance extracted dari setiap konstruk tidak sebaik nilai reliabilitas konstruk dimana nilai variance extracted untuk konstruk budgetary participation $(0,49)$, asimetri informasi $(0,46)$, dan budgetary slack $(0,46)$ menunjukkan less fit karena kurang dari 0,50. Sementara nilai variance extracted untuk konstruk tuntutan akan akuntabilitas dan perilaku individu dalam LSM menunjukkan nilai yang baik yaitu sebesar 0,57 dan 0,55 .

\section{d. Analisa Kesesuaian Model Struktural}

Pengujian kesesuaian struktural dilakukan terhadap koefisien-koefisien persamaan struktural dengan menspesifikasikan tingkat signifikansi tertentu. Model struktural signifikan jika memiliki nilai $\mathrm{t}$ lebih besar atau sama dengan 1,96 (Wijanto, 2006). Pada gambar 4.3. terlihat bahwa teidapat lima korelasi konstruk yang memiliki nilai $\mathrm{t}$ lebih besar dari 1,96 yaitu korelasi antara konstruk budgetary participation dengan konstruk budgetary slack (3,30), konstruk budgetary participation dengan konstruk asimetri informasi (2,31), konstruk tuntutan akan akuntabilitas dengan konstruk budgetary participation (9,34), konstruk tuntutan akan akuntabilitas dengan konstruk perilaku individu LSM, dan konstruk perilaku individu LSM dengan konstruk budgetary slack $(5,94)$. Terdapat pula dua korelasi konstnik yang memiliki nilai $\mathrm{t}$ marginal (signifikan pada $\mathrm{a}=10 \%$ ) yaitu 
korelasi antara konstruk tuntutan akan akuntabilitas dengan konstruk budgetary slack $(1,78)$ dan konstruk asimetri informasi dengan konstruk budgetary slack Pengujian kesesuaian juga dilihat dari model regresi berganda yaitu $R$ square $\left(\mathrm{R}^{2}\right)$. Dari keseluruhan hipotesis menghasilkan empat persamaan yang berarti terdapat empat model struktural yang diajukan. Keempat model struktural tersebut adalah sebagai berikut:

Regresi dengan $\mathrm{R}^{2}$ sebesar 0,51 berarti $51 \%$ dari variance konstruk budgetary slack dijelaskan secara signifikan oleh variabel budgetary participation, asimetri informasi, perilaku individu, dan tuntutan akan akuntabilitas. Jadi model dapat menjelaskan perubahan pada budgetary slack sebesar 51\%.

\section{e. Analisa Pengujian Hipotesa}

Hasil pengujian hipotesa 1 hingga hipotesa 10 berkaitan dengan budgetary participation, tuntutan akan akuntabilitas, asimetri informasi, perilaku individu LSM, dan budgetary participation dapat dilihat pada gambar 4.5. dan 4.6. Analisa hasil pengujian berdasarkan konstruk.

1. Analisa Ko-nstruk Budgetary Participation Pada model struktural antara variabel laten, terlihat adanya hubungan yang sesuai dengan model konseptual penelitian ini. Pada gambar 4.6. yang menampilkan nilai statistik $t$ dari model struktural, terlihat bahwa variabel laten budgetary participation mempunyai nilai $t$ value sebesar -3,30 yang berarti sangat signifikan pengaruhnya terhadap variabel budgetary slack dan mempunyai nilai tvalue sebesar -2,31 yang berarti signifikan pengaruhnya terhadap variabel asimetri informasi. Dengan demikian hasil pengujian ini mendukung Hipotesa 1 dan Hipotesa 8. Jadi semakin tinggi budgetary participation maka terjadi penurunan slack(HI). Sebaliknya semakin tinggi budgetary participation ternyata terjadi peningkatan asimetri informasi (H8).

- Analisa Hasil Pengujian Hipotesa 1 Terlihat bahwa partisipasi individu di dalam penyusunan budget; atau disebut budgetary participation, mempunyai dampak positif yang sangat signifikan pada slack dengan nilai $t$-3,30. Kesimpulan dari pengujian hipotesa ini adalah bahwa kebutuhan untuk menciptakan slack berkurang karena dengan partisipasi maka individu dalam hal ini direktur dan manajer merasa bahwa dirinya penting bagi masa depan LSM sehingga dalam berpartisipasi lebih mendahulukan kepentingan organisasi, untuk pencapaian target anggaran yang telah disetujui oleh pihak pemberi dana, daripada kepentingan individu (sejalan dengan pernyataan Argyris, 1952 dalam Milani, 1975). Hal ini terlihat dari pertanyaan-pertanyaan 8, 11, 12, dan 9.

Substansi pada pertanyaan 8, 11, dan 12 menunjukkan responden tersebut penting bagi masa depan LSM 
dimana diberi kesempatan untuk berpartisipasi, kehadiran penting dalam proses penyusunan budget dan idenya penting dalam melakukan perbaikan budget. Sementara berdasarkan pertanyaan 9, terlihat bahwa dalam proses penyusunan anggaran responden tidak mementingkan kebutuhan pribadi namun lebih mengutamakan kepentingan organisasi, mencapai tujuan organisasi (Becker dan Green, 1962; Hanson, 1966; Lowin, 1968; dan Brownell, 1982a).

Budgetary participation dengan perilaku positif ini tentu saja membawa pengaruh yang positif pula terhadap slack dimana kesempatan untuk berpartisipasi lidak digunakan untuk memenuhi kepentingan pribadi namun demi masa depan LSM sehingga kesempatan yang besar untuk berpartisipasi justru menurunkan slack. Bukti ini mendukung penelitian terdahulu yang dilakukan oleh Schiff dan Lewin (1970), Onsi (1973), Cammann (1976), Merchant (1985), dan Fitri (2004).

\section{- Analisa Hasil Pengujian Hipotesa 8.}

Hasil penelitian ini menguatkan studi yang dilakukan Van der Stede (2001) yang menemukan bukti bahwa partisipasi memiliki korelasi positif dengan asimetri informasi yang berarti semakin tinggi partisipasi, justru semakin tinggi asimetri informasi. Partisipasi penting untuk memperoleh informasi yang berguna dalam memprediksi perilaku berkaitan dengan budget (Swieringa dan Moncur, 1975, dalam Collins, 1978). Jika dikaitkan dengan landasan teori mengenai budgetary participation dan penjelasan di atas berkaitan dengan Hipotesa 1, maka dapat dipahami jika direktur dan manajer akan melakukan yang terbaik demi masa depan LSM dengan tidak memberikan seluruh informasi khusus yang dimilikinya yang dapat digunakan pihak pemberi dana untuk menekan LSM atau melakukan kontrol dan evaluasi yang kontra produktif terhadap LSM dalam menjalankan misi sosialnya.

2. Analisa konstruk Tuntutan akan Akuntabilitas

Variabel laten tuntutan akan akuntabilitas mempunyai nilai t-value sebesar 1.78, yang berarti hanya signifikan secara marginal mempengaruhi variabel budgetary slack. Hubungannya dengan variabel lain yang mempengaruhi variabel budgetary slack: (1) mempunyai nilai t-value sebesar 9.34 yang berarti sangat signifikan pengaruhnya terhadap variabel budgetary participation', (2) mempunyai nilai $t$-value sebesar 1.45 yang tidak signifikan 
pengaruhnya terhadap variabel asimetri informasi; dan (3) mempunyai nilai $t$ value sebesar 3,59 yang signifikan pengaruhnya terhadap variabel perilaku individu LSM. Dengan demikian maka Hipotesa 2, Hipotesa 5 dan Hipotesa 7 memiliki bukti yang signifikan. Sementara Hipotesa 6 kurang terbukti signifikansi pengaruh tuntutan akan akuntabilitas terhadap asimetri informasi.

- Analisa Hasil Pengujian Hipotesa 2. Hasil pengujian untuk membuktikan Hipotesa 2 ternyata menunjukkan pengaruh marjinal tuntutan akan akuntabilitas pada budgetary slack. Ini berarti mendukung Hipotesa 2 dimana tingginya tuntutan akan akuntabilitas membawa dampak negatif yaitu meningkatkan slack. Jadi semakin tinggi tuntutan pihak pemberi dana akan akuntabilitas LSM, maka semakin tinggi pula kebutuhan LSM untuk menciptakan slack.

Berdasarkan kuesioner yang diisi oleh responden maka terlihat pertanyaan 22, 25, dan 26 yang berkaitan dengan tuntutan akan akuntabilitas serta pertanyaan 38, 39, dan 40 yang berkaitan dengan budgetary slack menjadi pemicu kebutuhan untuk menciptakan slack. Pertanyaan 22 berkaitan dengan tuntutan akan laporan aktivitas yang terperinci; pertanyaan 25 berkaitan dengan tuntutan untuk melakukan transparansi laporan keuangan yang sudah diaudit kepada publik; dan pertanyaan 26 berkaitan dengan kebijakan dan prosedur penggunaan dana yang diperoleh. . Pertanyaan 38 berkaitan dengan produktivitas untuk mencapai anggaran. Pertanyaa 39 berkaitan dengan target anggaran yang sulit untuk dicapai. Pertanyaan 40 berkaitandengan anggaran yang penting bagi LSM.

Terlihat bahwa tuntutan pihak pemberi dana akan akuntabilitas berpengaruh negatif (kontra produktif) pada kerja-kerja yang dilakukan oleh LSM untuk mencapai misi sosialnya. Khususnya LSM yang menjadi target responden adalah yang berada di daerah yang tertimpa bencana yang amat diharapkan dapat membantu korban bencana. Kondisi korban bencana yang tidak dapat menunggu harus menjadi prioritas sementara LSM dituntut oleh pihak pemberi dana untuk memberikan dokumen lengkap berkaitan dengan aktivitas dan penggunaan dana yang diberikan sesuai prosedur yang ditetapkan. Dengan demikan untuk dapat menjalankan misi sosialnya dengan baik dibutuhkan slack agar misi sosial tidak terhenti di tengah jalan karena kehabisan dana atau dana belum turun karena menunggu klarifikasi dari auditor atas laporan keuangan dan laporan aktivitasnya misalnya. 
Hasil ini sejalan dengan temuan Penelitian Onsi (1973), Cammann (1976) dalam Merchant (1985), dan Otley (1978) yang menunjukkan adanya hubungan positif antara budgetary slack dengan sistem kontrol budget yang ketat, yang menekankan pada pencapaian target budget, oleh manajemen puncak. Relasi positif ini berarti semakin tinggi kontrol budget untuk pencapaian target budget maka cenderung semakin tinggi pula kebutuhan untuk menciptakan slack.

- Analisa Hasil Pengujian Hipotesa 5. Hasil pengujian Hipotesa 5 menunjukkan bahwa terdapat korelasi positif yang sangat signifikan (nilai $t$ sebesar 9,34) antara tuntutan akan akuntabilitas dengan budgetary participation dengan kesimpulan bahwa tingginya tuntutan akan akuntabilitas akan mempengaruhi peningkatan partisipasi dalam proses penyusunan anggaran. Jika dikaitkan dengan pertanyaan-pertanyaan berkaitan dengan budgetary participation (lihat analisa hipotesa 1) dan pertanyaan-pertanyaan berkaitan dengan tuntutan akan akuntabilitas serta budgetary slack (lihat analisa hipotesa 2), maka terlihat kaitan yang erat bahwa tingginya tuntutan akan akuntabilitas oleh pihak pemberi dana menyebabkan kebutuhan LSM untuk menciptakan slack yang dapat dilakukan jika kesempatan berpartisipasi juga tinggi.

Hasil temuan pada penelitian ini sejalan dengan Hanson (1966) yang mengungkapkan bahwa dalam sistem kontrol yang menekankan pada pencapaian hasil sesuai budget menyebabkan manajer membutuhkan budget yang fleksibel melalui budgetary participation. Studi Van der Stede (2001) menyimpulkan pula hal yang sama bahwa semakin tinggi tuntutan akan akuntabilitas, maka semakin tinggi pula kebutuhan untuk berpartisipasi dalam penyusunan budget.

- $\quad$ Analisa Hasil Pengujian Hipotesa 7. Hasil penelitian ini membuktikan bahwa adanya terdapat korelasi positif yang signifikan antara tuntutan akan akuntabilitas dengan perilaku individu (nilai $t$ sebesar 3,59). Pertanyaanpertanyaan yang terkait dengan perilaku individu LSM di antaranya adalah pertanyaan 30, 31, dan 33. Berdasarkan pertanyaan-pertanyaan tersebut, responden terlihat merasa tertekan akan tuntutan untuk pencapaian anggaran dan bekerja keras untuk menghasilkan output lebih baik dari harapan pihak pemberi dana sehingga mempengaruhi kemudahan dalam mendapatkan dana yang diperlukan oleh LSM di masa yang akan datang untuk programprogram selanjutnya. Jika dikaitkan 
pertanyaan-pertanyaan berkaitan

perilaku individu LSM dengan tuntutan akuntabilitas (lihat analisa hipotesa 2) maka tidak mengherankan tingginya tuntutan akan akuntabilitas berdampak pada tingginya perasaan tertekan dari responden dalam menjalankan tugasnya. Hasil studi ini menguatkan studi Hopwood (1972) dalam Van der Stede (2000), Onsi (1973) dan Cammann (1976) dalam Merchant (1985) membuktikan bahwa sistem kontrol yang ketat berpengaruh pada perilaku bawahan yang tertekan dan berusaha melindungi diri (defensive subordinate responses).

3. Analisa Konstruk Asimetri Informasi

Variabel laten asimetri informasi mempunyai nilai t-value sebesar 1.76 yang berarti hanya signifikan secara marginal mempengaruhi variabel budgetary slack dan mempunyai nilai t-value sebesar 0.47 yang berarti tidak signifikan pengaruhnya terhadap variabel perilaku individu LSM. Dengan demikian ditemukan bukti yang mendukung Hipotesa 3 namun tidak ditemukan bukti untuk mendukung Hipotesa 9.

Berdasarkan pertanyaan-pertanyaan yang terkait dengan asimetri informasi yaitu pertanyaan 16 hingga pertanyaan 21 terlihat bahwa terdapat informasi khusus yang dimiliki oleh responden yang tidak dimiliki oleh pihak pemberi dana Jika dikaitkan dengan perasaan tertekan akan tuntutan akan akuntabilitas yang tinggi dari pihak pemberi dana maka wajar jika responden memiliki kecenderungan untuk menyimpan atau tidak membagi seluruh informasi khusus yang dimilikinya (defensive subordinate responses) demi kepentingan LSM tersebut di masa yang akan datang. Informasi khusus yang dimiliki responden tersebut antara lain berkaitan dengan aktivitas yang dijalankan, output yang sebenarnya dari aktivitas yang dijalankan, kinerja dan pola bekerja yang sesungguhnya, dan pengaruh eksternal terhadap aktivitas yang dijalankan.

Dengan demikian hasil penelitian ini menguatkan hasil penelitian Merchant (1985) dan Young (1985) yang membuktikan bahwa rendahnya asimetri informasi menyebabkan atasan memiliki kemampuan untuk mendeteksi kemampuan produktivitas yang sesungguhnya atau slack sehingga kecenderungan menciptakan slack menurun dan sebaliknya. Jadi dapat disimpulkan jika asimetri informasi rendah, maka slack juga rendah dan sebaliknya jika asimetri informasi tinggi, maka slack juga tinggi. Hal ini sejalan dengan Christensen (1982, dalam Young, 1985) yang menyatakan bahwa principal sulit untuk membujuk agent agar membagi informasi khusus yang dimilikinya. Adanya asimetri informasi justru meningkatkan kesempatan untuk menciptakan slack karena kurangnya informasi yang dimiliki atasan dalam mengevaluasi kinerja bawahan 
mendorong bawahan untuk tidak membagi inforamsi khusus yang dimilikinya (Christensen, 1982 dalam Young, 1985).

4. Analisa Konstruk Perilaku Individu LSM Variabel laten perilaku individu mempunyai nilai t-value sebesar 5,94 yang berarti memiliki pengaruh yang sangat signifikan terhadap variabel budgetary slack dan mempunyai nilai $t$ value sebesar -0.33 yang menunjukkan tidak signifikan pengaruhnya terhadap variabel budgetary participation. Jadi ditemukan bukti yang kuat untuk mendukung Hipotesa 4. Sementara berkaitan dengan Hipotesa 10 tidak ditemukan bukti.

Jika dikaitkan dengan pertanyaanpertanyaan mengenai perilaku individu LSM (lihat analisa hipotesa 7) fan budgetary slack (lihat analisa hipotesa 1 hingga 3) maka responden yang merasa tertekan mempunyai kebutuhan untuk menciptakan slack agar tekanan yang diterimanya dapat berkurang. Jadi semakin tertekan responden dalam menjalankan aktivitasnya, maka akan meningkat kebutuhannya untuk menciptakan slack agar budget lebih fleksibel dan mudah dicapai sehingga tekanan dari pihak pemberi dana yang dihadapi berkurang. Literatur berkaitan dengan perilaku menyatakan hal yang sama bahwa slack merupakan bias manajerial, respon defensif, dan perilaku untuk melonggarkan budget (Hopwood,
1976; Kerr, 1979; Schein, 1979; serta Anthony dan Dearden, 1981; dalam Merchant 1985). Onsi (1973) menemukan adanya relasi positif antara budgetary slack dengan perilaku tertekan untuk mencapai target budget.

Hasil penelitian ini sejalan dengan prediksi Schiff dan Lewin (1970), Cammann (1976), dan Collins (1978) bahwa jika manajer percaya akan adanya penghargaan jika target budget tercapai, maka mereka akan berupaya untuk menciptakan slack (perilaku terhadap tekanan akan pencapaian target budget). Hasil penelitian ini menguatkan hasil dari penelitian yang dilakukan oleh Lowe dan Shaw (1968) dalam Merchant (1985) dan penelitian Young (1985) yang membuktikan bahwa bawahan yang memiliki perilaku menghindari risiko akan berusaha menciptakan slack. Jadi perilaku memiliki dampak negatif terhadap slack berarti ada kecenderungan perilaku individu yang mengalami tekanan untuk menciptakan slack.

\section{KESIMPULAN DAN SARAN}

\section{Kesimpulan}

Berdasarkan hasil pengujian pada bab 4 dapat ditarik kesimpulan bahwa budgetary slack LSM, dipengaruhi oleh tingkat partisipasi individu LSM, tuntutan akan akuntabilitas dalam hal ini khususnya pihak pemberi dana, asimetri informasi antara pihak LSM dan pihak pemberi dana, dan perilaku individu LSM (pembuktian atas hipotesa 1 
hingga hipotesa 4). Hasil penelitian membuktikan bahwa perilaku individu LSM memiliki pengaruh negatif paling signifikan terhadap budgetaiy slack dengan nilai $t$ sebesar 5,94. Sementara tuntutan akan akuntabilitas dan asimetri informasi memiliki pengaruh negatif signifikan secara marjinal yang hampir sama besar (nilai t sebesar 1,78 dan 1,76). Hanya budgetaiy participation yang memiliki pengaruh positif yang kuat pada budgetaiy slack (nilai t sebesar -3,30)

Hasil pengujian membuktikan adanya korelasi positif antar variabel yang mempengaruhi budgetaiy slack. Budgetaiy participation terbukti memiliki korelasi positif dengan asimetri informasi dimana peningkatan asimetri informasi dipengaruhi oleh meningkatnya partisipasi. Tuntutan akan akuntabilitas terbukti memiliki korelasi yang kuat positif dengan budgetaiy participation dan perilaku individu LSM dengan signifikansi nilai t sebesar 9,34 dan 3,59. Jadi semakin tinggi tuntutan akan akuntabilitas dari pihak pemberi dana maka semakin tinggi pula tekanan yang dihadapi oleh individu sehingga semakin tinggi pula kebutuhan untuk dapat mempengaruhi budget melalui peningkatan partisipasi agar tekanan berkurang.

Tuntutan akan akuntabilitas tidak terbukti signifikan mempengaruhi asimetri informasi. Demikian pula halnya dengan asimetri informasi yang tidak terbukti memiliki pengaruh yang signifikan terhadap perilaku individu LSM dan tidak terbukti pula pengaruh perilaku individu LSM terhadap budgetary participation.

\section{Saran}

Saran peneliti untuk studi lanjutan:

1. Mengkaji variabel pengukuran untuk dapat mengembangkan variabel pengukuran yang lebih baik

2. Memperbanyak jumlah responden yang diteliti agar hasilnya lebih baik dengan jangka waktu pengumpulan data yang lebih panjang, enam bulan misalnya.

3. Jika sampel relatif banyak mungkin memisahkan manajer dan direktur dalam grup yang berbeda, begitu pula dengan LSM lokal dan asing, dansize LSM.

4. Mungkin perlu dikembangkan instiumen mengenai akuntabilitas menurut organisasi itu sendiri, pihak pemberi dana (upward accountability) dan publik khususnya masyarakat yang diberdayakan oleh LSM (downward accountability) dan diuji hasilnya. 


\section{DAFTAR PUSTAKA}

Antonioni, D. (1994),"The effects of feedback accountability on upward appraisal ratings", Personnel Psychology, 47, 349-356.

Argyris, Chris (1952),"The Impact of Budgets on People", New York: Controllership Foundation, Inc.

Becker, Selwyn dan David Jr.Green (1962),"Budgeting and Employee Behavior", The Journal of Business, 34 (Oktober), 392-402.

Bendell, Jem (2006),"Debating NGO Accountability", UN-NGLS Development Dossier, United Nations New York dan Geneva, 1-121

Brownell, Pete (1982a), "The Role of Accounting Data in Performance Evaluation, Budgetary Participative and Organizational Effectiveness", Journal of Accounting Research, 20 (Musim Semi), 12-27.

Bryan, J.F. dan E.A. Locke (1967),"Goal Setting as a Means of Increasing Motivation", Journal of Applied Psychology, 51, 274-277.

Chow, Chee W., Jean C. Cooper, dan William S. Waller (1988),"Participative Budgeting: Effects of a Truth-Inducing Pay Scheme and Information Asymmetry on Slack and Performance", The Accounting Review, Vol.63, No.l (January), 111-122.

Cotter, Jerry J. (1964),"Selected Behavioral Variables Associated with Participation in Budget Development", Unpublished PH.D. dissertation, Department of Management, University of Wisconsin, 1964.

Cyert, R.M. dan J.G.March (1963), "A Behavioral Theory of the Finn", Englewood Cliffs, NY: Prentice-Hall.

Dunk, Alan S. dan Hossein Nouri (1998), "Antecedents of Budgetary Slack: A Literature Revies and Synthesis", Journal of Accounting Literature, 17, 72-96.

Dunk, Alan S. dan H.Perera (1997),"The Incidence of Budgetary Slack: A Field Study Exploration", Accounting, Auditing, and Accountability Journal, 10 (Mei), 649-664.

Dunk, Alan S. (1993), "The Effect of Budget Emphasis and Information Asymmetry on the Relation between Budgetary Participation and Slack", The Accounting Review, vol.68, No.2 (April), 400410. 
Ebrahim, A. (2003), "Accountability in Practice Mechanisms for NGOS", World Development, 31 (Mei), 813-829.

Fitri, Yulia, SE.MSi.Ak. (2004),"Pengaruh Informasi Asimetri, Rirtisipasi Penganggaran dan Komitmen Organisasi terhadap Timbulnya Senjangan Anggaran: Studi Empiris pada Universitas Swasta di Kota Bandung", Seminar Nasional Akuntansi (2-3 Desember), 581-597.

George, Jenniver M. dan Gareth R.Jones (2002), "Organizational Behavior", Prentice Hall, International Edition, 3rd Edition.

Gibbins, Michael dan James D.Newton (1994),"An Empirical Exploration of Complex Accountability in Public Accounting", Journal of Accounting Research, 32 (Musim Gugur), 165-186.

Hansen, Stephen C, David T.Otley, dan Wim A.Van der Stede (2003),"Practice Developments in Budgeting: An Overview and Research Perspective", Journal of Management Accounting Research, (VS).

Hanson, Ernest I. (1966),"Budgetary Control Function", The Accounting Review, 41 (April), 239-243.

Hofstede, G.H. (1967),"Thc Game of Budget Control", The Netherlands: Koninklijkc Van Gorcum and Comp.N.V. Assen.

Hornstein, Harvey A. et al (1968),"Influence and Satisfaction in Organizations: A Replication", Sociology) of Education, 41 (Musim Gugur), 380-389.

Http://www.inteniationalbudget.org/resources/library/civilsociety/budRet analysis

IAI (2004), "Standar Akuntansi Keuangan", Jakarta, Penerbit Salemba Empat.

Johns, Gary dan John Roskam (2004),'The Protocol: Managing Relations with NGOs", The Institute of Public Affairs, (April).

Joshi, A. dan M. Moore (2000), "Enabling Environments: Do Anti-Poverty Programmes Mobilise The Poor?", Journal of Development Studies.

Kennis, J. (1979),"Effect of Budgetary Goal Characteristics on Managerial Attitudes and Performance", The Accounting Review, (April).

Keystone's Survey Results (2006),"Downward Accountability to Beneficiaries: NGO and Donor Perspectives", Keystone Reporting : Accountability for Social Change, (Juni), 118. 
Kilby, Patrick (2004), "Accountability for Empowerment: Dilemmas Facing NonGovernmental Organisations", Working Paper of the Asia Pacific School of Economics and Government, The Australian National University, Januari, 1-23.

Klimoski, R.J. dan L. Inks (1990),"Accountability Forces in Performance Appraisal', Organizational Behavior and Human Decision Processes, 45, 194-208.

Leibenstein, H (1979),"X-Efficiency: From Concept to Theory", Challenge (SeptemberOktober), 13-22.

Lewis, Debra (2006),"Understanding the Budget", Women 's Issues Network of Belize, (April), 1-90.

Linn, Gary dan K.Michael Casey, Gene H Johnson dan T.Selwyn Ellis (2001), "Do Broad Scope Management Accounting Systems Moderate The Effects of Budget Emphasis, Budget Participation, and Perceived Environmental Uncertainty on The Propensity to Create Budgetary Slack".

Lowe, E.A. dan R.W.Shaw (1968), "An Analysis of Managerial Biasing: Evidence from a Company's Budgeting Process", Journal of Management Studies (Oktober), 304-315.

Lowin, Aaron (1968)," Participative Decision-Making: A Model, Literature Critique, and Prescriptions for Research", Organization Behavior and Human Performance, 3 (Februari), 68-106.

Mango(2006),"Money-Budgeting, Accounting and Fund-Raising", www.mango.org.uk, (Maret), 1-21. ."

Manitoba Health (1999),"Achieving Accountability", (Agustus), 1-9.

Masyarakat Transparansi Indonesia (2005),"Panduan Pengawasan Keuangan Daerah: Wawasan dan Instrumen Monitoring Keuangan Daerah", Penerbit: Masyarakat Transparansi Indonesia-Uni Eropa, Jakarta.

Merchant, Kenneth A. (1985), "Budgeting and the Propensity to create Budgetary Slack", Accounting, Organisation and Society, 10, 201-210.

Milani, Ken (1975), "The Relationship of Participation in Budget-Setting to Industrial Supervisor Performance and Attitudes: A Field Study", The Accounting Review, vol.50, No.2 (April), 274-284.

Morse, Nancy C. dan E. Reimer (1956),"Experimental Change of a Major Organizational Variable", Journal of Abnormal and Social Psychology, 51, 120-129. 
Otley, David dan Alexander Fakiolas (2000),"Reliance on Accounting Performance Measures: Dead End or New Beginning?', Accounting, Organisation and Society, 25, 497-510.

Onsi, Mohamed (1973,"Factor Analysis of Behavioral Variables Affecting Budgetary Slack", The Accounting Review, Vol.48, No.3 (July), 535-548.

Salamon, L.M., Hems L.C., dan Chinnock K. (2000), "The Non-Profit Sector: For What and For Whom? Working papers of the Johns Hopkins Comparative Non-Profit Sector Project", the John Hopkins Center for Civil Society Studies, Baltimore, 37.

Sales, Stephen M. (1966),"Supervisory Style and Productivity: Review and Theory", Personnel Psychology, 24 (Musim Gugur), 275-286.

Schiff, M dan A.Y. Lewin (1968), "Where Traditional Budgeting Fails", Financial Executive (Mei), 50-62.

Scott, William R. (2000), "Financial Accounting Theory'\ Edisi Kedua, Prentice Hall Canada Inc., Scarborough, Ontario.

Sekaran, Uma (2003),"Research Methods for Business: A Skill Building Approach", Edisi Keempat, John Wiley and Sons, Inc., USA.

Stedry, Andrew C.(1967),"Budget Control and Cost Behavior, Markham Publishing Company.

Titi, V dan N. Singh (1995), "Empowerment for Sustainable Development: Towards Operational Strategies", Zed Booh. Nova Scotia.

Wijanto, Dr.Setyo Hari (2006),"Catatan Kuliah: Structural Equation Modeling dengan Lisrel 8.7", FEUI Pascasarjana Ilmu Manajemen, (Agustus).

Young, S.Mark (1985),"Participative Participative Budgeting: The Effects of Risk Aversion and Asymmetric Information on Budgetary Slack", Journal of Accounting Research, 23 (Musim Gugur), 829-842. 